\section{A multiple-choice airstream design for olfactory discrimination training of small animals ${ }^{1}$}

JOHN M. WILLIAMS and BURTON M. SLOTNICK, COLUMBIA UNIVERSITY, New York, New York 10027

A multiple wind-tunnel olfactory discrimination apparatus is described and evaluated. The apparatus allows for the simultaneous presentation of odor or visual cues and permits direct comparisons to be made on visual and olfactory discrimination performance.

Previous studies using still-air presentation of olfactory stimuli suggest that olfactory discriminations are difficult to establish. Eayrs and Moulton (1960), using several still-air designs, concluded that olfactory training of rats requires close spatial contiguity of cue and reward and that "... the sense of smell possesses weak orientating properties by comparison with those exerted by other modalities." In contrast, recent experiments using airstream designs which immerse the $S$ in a controlled stream of moving air (Pfaffman, Goff, \& Bare, 1958; Goff, 1961; Henton, Smith, \& Tucker, 1966) have shown olfactory discriminations to be relatively easy to establish. The present report explores the usefulness of an airstream design which incorporates two independent wind tunnels that allows $S$ to sample freely between two simultaneously-available odors. The successive acquisition of several olfactory discrimination problems is described for two rats.

\section{METHOD \\ Subjects \\ Two adult female albino rats obtained from Carworth Farms were used. S 1 was experimentally naive, and $S 2$ previously had been trained in a Skinner box to barpress for water under various schedules of reinforcement. Both Ss were maintained on a $23.75 \mathrm{~h}$ water deprivation schedule.}

\section{Apparatus}

The test chamber was a modified soft-drink cooler box. One end wall of the box was replaced with a panel that contained a solenoid-operated water dipper mounted between two $2 \times 2 \times 8$ in. high stainless steel wind tunnels. Each wind tunnel contained a standard Lehigh Valley pigeon key with a stimulus light mounted behind the translucent paddle of the key. A $30 \mathrm{cfm}$ exhaust fan was mounted at the top and a $2 \times 4 \mathrm{~cm}$ inlet for the delivery of odorized air was fitted to the base of each tunnel.
A schematic diagram of the odorizer and wind tunnel is given in Fig. 1. The odorizer consisted of a variable-pressure air pump, two $500-\mathrm{ml}$ filtering flasks (altered by a glassblower to have two extra $1 / 2$-in. OD outlets at the neck) to contain odorants, and solonoid-operated Skinner valves to control the selection and flow of odorized air. Medical grade Tygon tubing was used between odorizer components. As shown in Fig. 2, wind tunnels $A$ and $B$ received odorized air from flasks $A$ and $B$, respectively. Energizing the 3-way valves reverses this selection. Energizing the 2-way valves cuts off the flow of odorized air to the wind tunnels. During operation, the air pump was adjusted so that the latency to reverse odors in the wind tunnels was less than $1 \mathrm{sec}$, and the speed of the odorized air stream was about $0.6 \mathrm{~m} / \mathrm{sec}$ at the tunnel intakes.

\section{Odorants}

In the demonstration cited here, we investigated only the usefulness of the apparatus in training simple odor discriminations; accurate quantitative work would require a more sophisticated odorizer such as those described in the reports cited above. In particular, the use of glass or Teflon tubing should be used to conduct the odorants and appropriate air-filtering devices should be used to

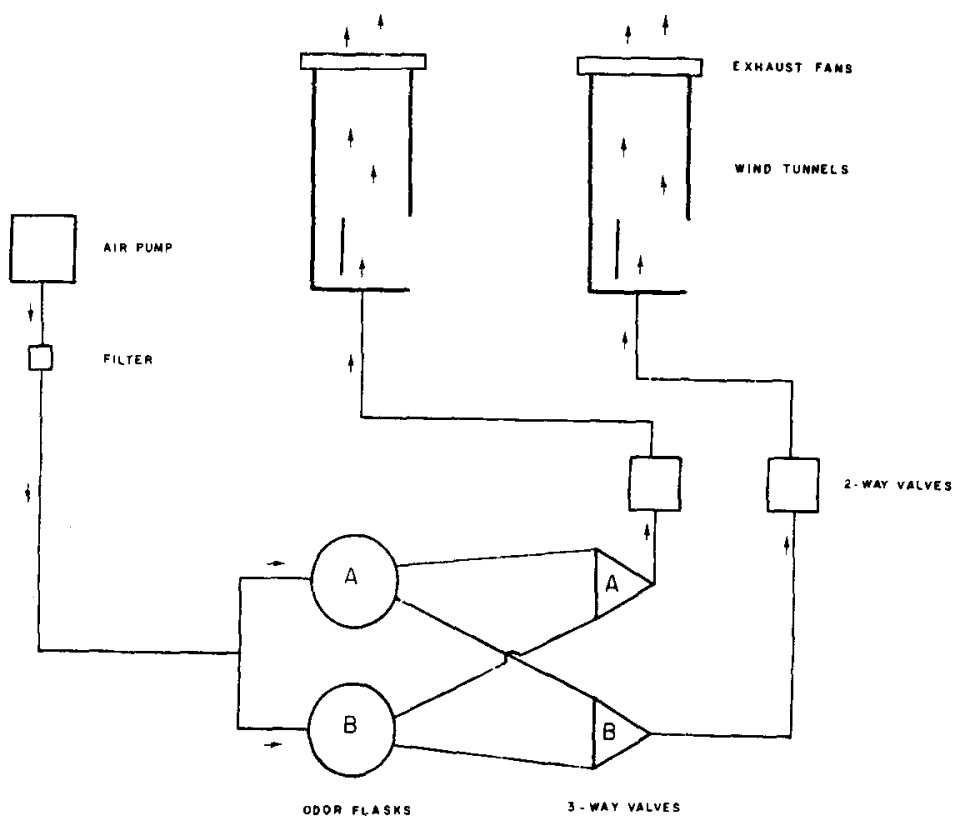

Fig. 1. Schematic diagram of the odorizer. The arrows indicate direction of air flow. The solenoid valves were obtained from Skinner Precision Industries Co.: 3-way valves Model No. V54DB2100 and 2-way valves Model No. V52DB2100. A pressure-vacuum air pump (particle filter attached) from Fischer Scientific Co. was used. insure a clean air source from the pressure pump. A series of odorants were used which were highly discriminable and, when sampled by the investigators, were judged to be nonirritating. The pairs of odorants used for $S 1$ in two successive discrimination problems were as follows: aromatic pipe tobacco (st) vs groun coffee (s-) and soy sauce diluted with eight parts of water (st) vs reconstituted lime juice (s-). Stimuli for $S 2$ in two discrimination problems were: ground coffee (st) vs aromatic pipe tobacco (s-), and dried dill seed (st) vs dried rosemary leaves ( $s-$ ). In each case a small amount of the odorant substance was placed in the directing a stream of air over it.

\section{Training Procedure}

Each rat first was acclimated to the noise of the fans and pump and response shaped to keypress for a $.05 \mathrm{cc}$ water reward. Acclimation to the chamber and response shaping (about 30 reinforcements were delivered on each key) required approximately $3 \mathrm{~h}$ for each $\mathrm{S}$.

The training procedures differed slightly for the two Ss. S 1 was given visual discrimination training followed by olfactory discrimination training. During visual training, the 2 -way valves were shut and a modified discrete trial procedure was used in which trial $(\mathrm{Tr})$ periods alternated with time-out (TO) periods. During the Tr periods, responses to the correct (illuminated) key were reinforced with water on a VI-15 sec schedule. After one reinforcement, a TO period was initiated appropriate flask and volatilized simply by 


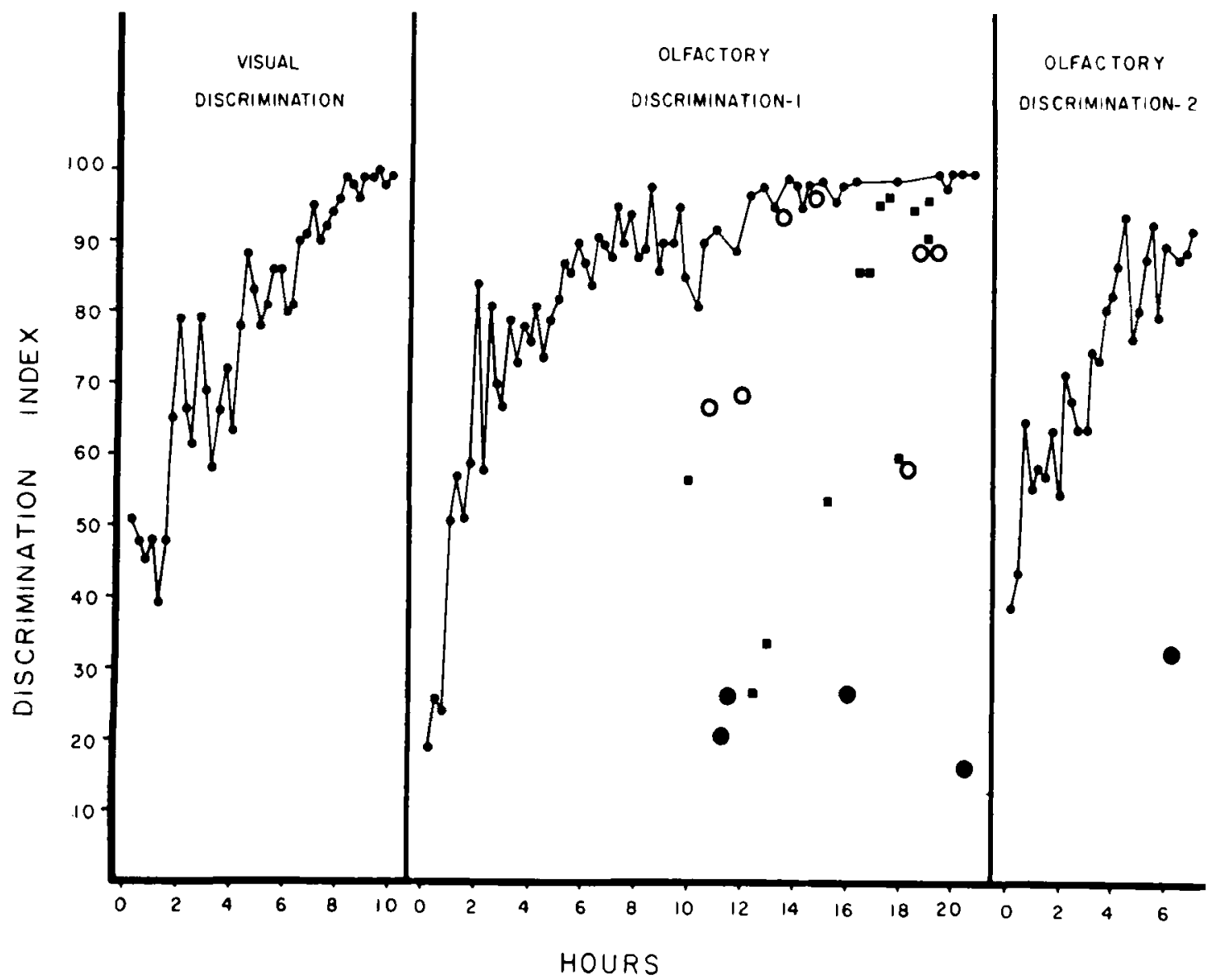

Fig. 2. The first rat's performance on one visual and on two successive two-odor olfactory discriminations. Performances during the interpolated $15-\mathrm{min}$ tests are shown also. Figure symbols are coded as follows: Large filled circles = no-cues; open circles = st only; squares $=$ s- only.

during which the house light was on and key lights were off. Reentry into the next $\mathrm{Tr}$ period (and continuation of the VI schedule) was contingent upon S's meeting a $20-\sec$ no-response criterion during TO. The key illuminated during successive $T r$ periods altemated randomly right and left, and throughout each $T r$ period a $5-\mathrm{sec}$ changeover delay was in effect. For olfactory discrimination training, the key lights were off and odorized airstreams in the tunnels replaced the lights as discriminative stimuli during the $\mathrm{Tr}$ periods. Presentations of stimuli, response contingencies, and reinforcements were programmed by a relay switching curcuit. Correct and incorrect response totals on each key during the $T r$ periods were read each $15 \mathrm{~min}$ from counters.

Following acquisition of the first olfactory discrimination, 15-min tests were interpolated from time to time in order to determine the effect of altering the olfactory cues. Three different kinds of tests were made: (1) "no-cues" tests during which the 2-way valves were shut and wind-tunnel inlets were open to room air; (2) "st only" tests during which the sodorized airstream was cut off; and (3) "s- only" tests during which the st odorized airstream was cut off. From the no-cues tests, we could determine whether or not discriminative performance cou'd be maintained by meens of extran:ous cues such as apparatus noises, ef..., in the absence of odorized airstrearıs. It was hoped that the single-odor (st only and sonly) tests might tell us something about the specific odor cues used to maintain discriminative performance.

After each olfactory discrimination had been well established, we tested to see if the discriminative cues in the airstreams were in fact the intended odor cues by switching the odorants in the flasks; the flasks were emptied and cleaned, st and swere replaced in the flasks opposite to the ones they had last occupied, and two leads were reversed in the relay circuitry so that the reinforced key remained paired with the st stimulus. Nonodor cues in the airstreams or odor cues not emanating from st and s- would be reversed and would not support discriminative responding after the switching procedure was carried out.

The second rat (S 2) was not given visual discrimination training but was started on its filst olfactory problem immediately after response shaping had been completed. Following acquisition of its first olfactory discrimination, S 2 was given $31 / 4 \mathrm{~h}$ of continued training under no-cue test conditions as described above. $A$ second olfactory discriminaticn nroblem was then introduced, and trainin, was terminated following acquisition. Throughout training, the TO period for : $\angle$ was only 2 sec.

For bott Ss, the odorizer flasks, stoppere and tubing were cleaned and reasse . bled in their original configuration before a new pair of odorants was introduced. For each pair, the new st was placed in the flask that last held $s-$, and vice versa, so that any possible olfactory trace cues remaining from the previous discrimination would not facilitate acquisition of the new problem.

The measure of performance was the discrimination index (DI), as defined by Millenson (1967).

\section{RESULTS}

Figure 2 shows $S$ l's acquisition of the visual discrimination and of the two consecutive olfactory discriminations that followed. 


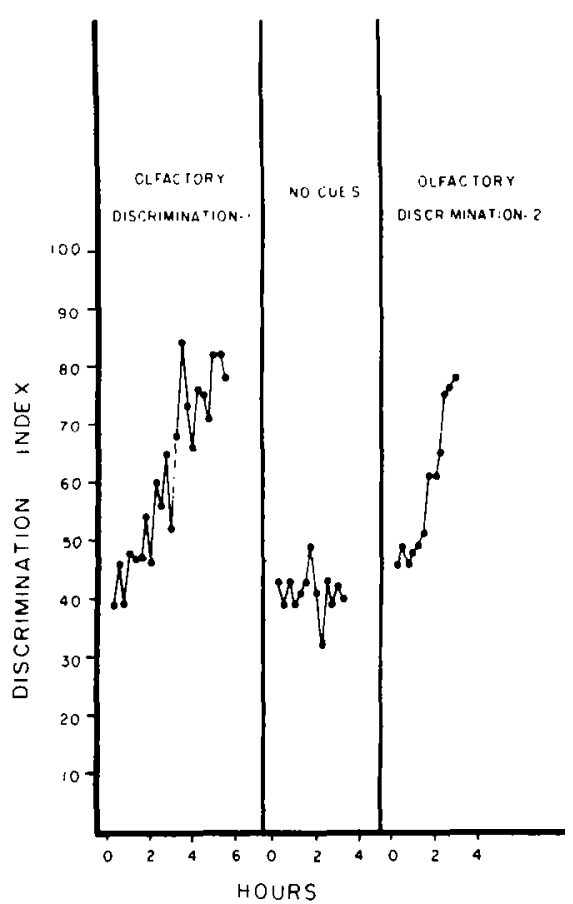

Fig. 3. The second rat's performance for a two-odor olfactory discrimination, a prolong no-cues test interval, and a second two-odor olfactory discrimination.

Virtually perfect performance on the visual problem was seen after approximately $7 \mathrm{~h}$ of training. By the end of visual training, S 1 was emitting 150-300 response per $15 \mathrm{~min}$ during the Tr periods and showing almost complete response inhibition during the TO periods. Following introduction of the first olfactory discrimination, response accuracy dropped well below $\mathrm{DI}=.5$ but rose gradually. After approximately $7 \mathrm{~h}$ of training, consistently high performance again was seen. Periodic observation of the animal during olfactory training indicated that at the beginning of each $T r$ period $S$ typically inserted its head into one of the wind tunnels; if the choice was correct, keypressing occurred with no noticeable hesitation; if incorrect, few or no responses were made and the animal quickly shifted to the other wind tunnel and began responding. During the TO periods, $S$ showed exploratory activity about the chamber but virtually no sampling of the wind tunnels. Introduction of the second olfactory problem again resulted in a drop in accuracy and a gradual acquisition of the new discrimination.

The results of the interpolated tests given during S l's first olfactory discrimination are shown in the second panel of Fig. 2. During no-cues tests, performance quickly dropped to levels below $\mathrm{DI}=.5$ but rose immediately when the olfactory cues were reintroduced. Performance during single-odor presentations was consistently poorer than that seen when both airstreams were available, although over repeated single-odor tests performance rapidly improved. Discrimination performance was not disnupted by switching the odorants in the flasks.

Figure 3 shows S 2's acquisition of the first olfactory discrimination, subsequent testing under the no-cues condition, and acquisition of the second olfactory discrimination.

By the end of training, both Ss were emitting 300-700 responses and earning 20-35 reinforcements per $15 \mathrm{~min}$.

\section{DISCUSSION}

The immediate drop in accuracy of performance during the no-cues tests and the failure of odorant switching procedures to interfere with performance clearly demonstrated that odors were the discriminative cues being used during olfactory training. The failure of $S 2$ to perform better than chance during extended no-cues training, along with its rapid acquisition following reintroduction of olfactory cues, demonstrated that extraneous apparatus cues were not available as discriminative stimuli. S1's initial performance during the interpolated single-odor tests (see Fig. 2) suggests that both $\mathrm{st}$ and $\mathrm{s}-$ were being used to support discriminative performance.

In both Ss, performance during initial training and during the no-cues tests was consistently below DI .5. This probably is due to a VI schedule-induced tendency to persevere in responding on a given key when discriminative cues had not been learned or were not available. Better control of this perseverative tendency could probably be obtained by using other schedules of reinforcement such as a noncorrection discrete-trials procedure (Nevin, 1967).

The choice of an intertrial interval must take into account the potential confounding due to olfactory adaptation. In the present case the rate of acquisition and other aspects of performance for $S 2$ were comparable to those of $\mathrm{S} 1$ although only a 2-sec TO period was used. However, olfactory adaptation is undoubtedly a function of the odorants used and the parameters of stimulus presentation. As Bennett (1968) has demonstrated olfactory adaptation for the rat in a behavioral situation, it is clear that the potential confounding due to this variable represents a further methodological problem, particularly for quantitative work.

The present discrimination box differs from previous airstream designs in that the animal can sample between two simultaneously present odors on each trial. The opportunity for the animal to freely sample each odor does restrict the E's ability to quantify the stimulus accurately. Where such specification is essential either the successive odor presentation technique described by Braun et al (1967) must be used or appropriate modification of the simultaneous procedure must be devised. However, the present design offers the $\mathrm{E}$ several advantages: It allows access to several odorant cues prior to choice behavior, thus providing a discrimination situation similar to that used in simultaneóus visual or tactile discrimination training. The apparatus can be expanded easily to a 3-tunnel problem which will allow all of the manipulations necessary to explore olfactory control of complex discriminated operants including learning sets, matching to sample, and oddity problems (Cumming \& Berryman, 1965). Finally, it should be noted that simultaneous presentation of the discriminative cues allows $\mathbf{S}$ to make a large number of sampling decisions in a relatively short time. In subsequent work, we have found that an experienced $S$ will show acquisition of a new problem and stable performance within a single 2- or $2 \frac{1}{2}-\mathrm{h}$ training session. This type of performance may be advantageous for studying the effects of various short-acting physiological variables such as drugs, brain stimulation, or local anesthetics on the acquisition of olfactory discriminations.

\section{RFFER F N CF}

BENNETT, M. H. The role of the anterior limb of the anterior commissure in olfaction. Physiology \& Behavior, 1968, 3, 507-515.

BRAUN, J., WERMUTH, B., \& HABERLY, L. An olfactory discrimination apparatus: Modification of the basic "wind-tunnel" design. Psychonomic Science, 1967, 9, 515-516.

CUMMING, W. W., \& BERRYMAN, R. The complex discriminated operant: Studies of matching to sample and related problems. In D. J. Mostofsky (Ed.), Stimulus generalization. Stanford, Calif: Stanford University Press, 1965. Pp. 284-330.

EAYRS, J. T., \& MOULTON, D. G. Studies in olfactory acuity. I: Measurement of olfactory thresholds in the rat. Quarterly Joumal of Experimental Psychology, 1960, 12, 90-98.

GOFF, W. R. Measurement of absolute olfactory sensitivity in rats. American Journal of Psychology, 1961, 74, 384-393.

HENTON, W. W., SMITH, J. C., \& TUCKER, D. Odor discrimination in pigeons. Science, 1966 , 153, 1138-1139.

MILLENSON, J. F. Principles of behavioral analysis, New York: Macmillan, 1967.

NEVIN, J. A. Effects of reinforcement scheduling on simultaneous discrimination performance. Journal of the Experimental Analy sis of Behavior, 1967, 10, 251-260.

PFAFFMAN, C., GOFF, W. R., \& BARE, J. K. An olfactometer for the rat Science, 1958 , $128,1007-1008$

\section{NOTES}

1. This project was supported in part by USPHS Grant HD03131-02 to the second author. The authors would like to thank John A. Nevin for his advice during the preparation of the manuscript. 